Andréa Borghi Moreira Jacinto ${ }^{1,2}$ Daniel Adolpho Daltin Assis ${ }^{1,3}$ Pedro de Lemos MacDowell ${ }^{1,2}$ Taia Duarte Mota ${ }^{1,4}$

\title{
ÍNDIOS E LOUCOS: SOBRE TUTELA, RECONHECIMENTO DE DIREITOS E DESAFIOS PARA A EFETIVAÇÃO DA CIDADANIA NO CAMPO DA SAÚDE MENTAL*
}

The indigenous and the mad: About guardianship, recognition of rights and challenges for the realization of citizenship in the field of mental health

\author{
${ }^{1}$ Ministério da Saúde. Brasília/DF, Brasil. \\ ${ }^{2}$ Universidade de Brasília. Brasília/DF, Brasil. \\ ${ }^{3}$ Universidade Federal da Paraíba. João Pessoa/PB, Brasil. \\ ${ }^{4}$ Universidade de São Paulo. São Paulo/SP, Brasil. \\ Correspondência: Andréa Borghi Moreira Jacinto. E-mail: borghi1@yahoo.com.br
}

Recebido: 20/09/2017. Revisado: 16/03/2018. Aprovado: 19/03/2018.

\footnotetext{
*Este trabalho teve sua versão preliminar apresentada inicialmente no II Congreso Internacional Los Pueblos Indigenas de America Latina (Cipial), Santa Rosa, Argentina, de 20 a 24 de setembro de 2016. Trata-se de uma reflexão independente dos autores, desenvolvida a partir de um trabalho mais amplo no âmbito da CoordenaçãoGeral de Saúde Mental, Álcool e Outras Drogas, do Ministério da Saúde, e de seu Núcleo de Populações Tradicionais entre os anos de 2011 e 2015, também contando com a colaboração de Isadora Simões de Souza, Marina Rios Amorim e Jaqueline Tavares de Assis, sob a coordenação de Roberto Tykanori Kinoshita.
} 


\section{RESUMO}

O artigo propõe uma reflexão sobre a construção, no Brasil, de políticas públicas fundadas no reconhecimento da diferença, a partir de dois segmentos com histórias políticas e sociais distintas - povos indígenas e pessoas com transtornos mentais -, mas que enfrentaram uma mesma condição: a de, por muito tempo, terem sido excluídos como cidadãos devido a diferenças e, em nome delas, viverem até hoje situações extremas de violação de direitos. $\mathrm{O}$ trabalho tem como objetivo desenvolver um paralelo sobre o processo de reconhecimento dos direitos dos povos indígenas e, ao mesmo tempo, de reconhecimento dos direitos das pessoas com transtornos mentais, ambos possíveis a partir da promulgação da Constituição Federal de 1988. A análise tem como parâmetro o instituto da tutela anteriormente vigente no Brasil, que afetou de formas particulares esses dois segmentos sociais, deixando marcas culturais e ideológicas que continuam sendo enfrentadas para a efetivação e a consolidação dos novos direitos. Tratados como campos políticos e identitários diferentes entre si e bastante específicos, os paralelos a serem observados entre o campo dos direitos indígenas e o campo da saúde mental revelam histórias semelhantes, tanto em função das violações de direitos sofridas como pelo enfrentamento à normatização, normalização e estigmatização da diversidade. Enfim, são paralelos que dizem sobre movimentos sociais distintos, mas que revelam esforços semelhantes na luta pela construção e afirmação de uma cidadania fundada no reconhecimento da pluralidade.

\section{Palavras-Chave}

Direito Sanitário; Direito Indígena; Saúde Coletiva; Saúde Mental.

\section{ABSTRACT}

The article proposes a reflection on the construction of public policies in Brazil, based on the recognition of difference, from the perspective of two segments with distinct political and social histories - indigenous people and people with mental disorders. Both groups faced the same condition: they have been excluded as citizens for a long time, because of differences and, on the name of which, endure up to this day, extreme situations of violation of rights. The purpose of this paper is to develop a brief parallel on the process of recognition of the rights of indigenous people and, at the same time, the recognition of the rights of people with mental disorders, both made possible by the promulgation of the Federal Constitution of 1988. The analyses has as parameter the guardianship rules previously in force in Brazil, which affected these two social segments in a particular way, leaving cultural and ideological marks that continue to be confronted for the effectiveness and consolidation of the new rights. Treated as quite different and specific political and identity spheres, the parallels observed between the spheres of indigenous rights and mental health reveal similar stories, both regarding violations of rights, as well as the confrontation with normalization and stigmatization of diversity. Ultimately, they are parallels that say about distinct social movements, but which reveal similar efforts in the struggle for the construction and affirmation of a citizenship based on the recognition of plurality.

\section{Keywords}

Health Law; Indigenous Law; Mental Health; Public Health. 


\section{Introdução}

Ora, os nossos índios ou são cidadãos brasileiros ou não: para o serem, não cumprem nenhuma das obrigações das leis, e andam vadiando e com as orelhas e beiços furados, em vez de serem guardas nacionais e vestir uniformes etc. Não sendo, ou não estando neste jogo, por incapacidade moral, como diz a Constituição, não pode a lei - o direito civil - ver neles mais que uma gente estranha ao pacto social, que abusa da piedade que com eles se tem [...] E não é vergonha no meio de um país civilizado aturar tais canibais? (Francisco Adolfo de Varnhagen, 1851)

Depois da guerra, dissemos nós, o autor quer para os indígenas a escravidão; mas não tendo coragem de pedi-la abertamente, disfarça-a, acrescentamos, com o nome de tutela ou protetorado. Em verdade quem será tão ingênuo que não compreenda o que é uma tutela desse gênero, que recebe por paga o serviço do tutelado?

(Manuel Antônio de Almeida, 1851, em resposta a Varnhagen) ${ }^{1}$

O presente texto propõe uma reflexão sobre a construção, no Brasil, de políticas públicas fundadas no reconhecimento da diferença, a partir de dois segmentos com histórias políticas e sociais distintas, mas que enfrentaram uma mesma condição - a de, por muito tempo, terem sido excluídos como cidadãos em razão de diferenças e, em nome destas, viverem ainda hoje situações extremas de violação de direitos. O trabalho tem como objetivo desenvolver um breve paralelo sobre o processo de reconhecimento dos direitos dos povos indígenas e, ao mesmo tempo, de reconhecimento dos direitos das pessoas com transtornos mentais, ambos possíveis a partir da promulgação da Constituição Federal de $1988(\mathrm{CF} / 88)^{2}$.

A análise tem como parâmetro o instituto da tutela anteriormente vigente no Brasil, que afetou de formas particulares esses dois segmentos sociais, deixando marcas culturais e ideológicas que continuam sendo enfrentadas para a efetivação e a consolidação dos novos direitos. Subjacente ao instituto da tutela, encontram-se as noções de capacidade e autonomia como balizadores normativos - logo, normalizadores - acerca da inclusão e exclusão desses segmentos populacionais no rol de direitos, sobretudo os direitos de liberdade.

Tomados como campos políticos e identitários distintos entre si e bastante específicos, os vários paralelos a serem observados entre o campo dos direitos

\footnotetext{
${ }^{1}$ Sobre o debate entre Francisco Adolfo de Vernhagen e Manuel Antônio de Almeida, ver CUNHA, Cilaine Alves. Apresentação de "Civilização dos indígenas. Duas palavras do autor do Memorial Orgânico", de Manuel Antônio de Almeida. Teresa revista de Literatura Brasileira, São Paulo, v. 17, p. 191-199, 2016. ISSN Eletrônico: 2447-8997. Disponivel em: <https://www.revistas.usp.br/teresa/article/view/127373/124575>. https:// doi.org/10.11606/issn.2447-8997.teresa.2016.127373.

${ }^{2}$ BRASIL. Constituição da República Federativa do Brasil de 1988. Disponível em: <http://www.planalto.gov. br/ccivil_03/constituicao/constituicao.htm>. Acesso em: 05 set. 2017.
} 
indígenas e o campo da saúde mental revelam histórias semelhantes, tanto em função de violações de direitos sofridas como pelo enfrentamento à normatização, normalização e estigmatização da diversidade. São paralelos que dizem sobre movimentos sociais distintos, mas que revelam esforços semelhantes na luta pela construção e afirmação de uma cidadania fundada também no reconhecimento da pluralidade.

\section{Paralelos entre o campo dos direitos indígenas e o campo da saúde mental: da tutela ao reconhecimento de direitos}

Partindo da apresentação de diferentes processos sócio-históricos e jurídicos, explorou-se alguns dos paralelos entre a razão tutelar acionada pelo Estado que foi direcionada aos povos indígenas no Brasil e a que foi construída para controlar e invalidar pessoas com sofrimentos e transtornos mentais.

De início, importa sinalizar que, desde que recebem tratamento legal distinto na sociedade brasileira, loucos e indígenas são aproximados, em diferentes graus, por via de mesma classificação de incapacidade (civil) e inimputabilidade (penal) - a partir das noções de discernimento (não) atribuído aos primeiros e de adaptação à civilização, imposta aos segundos.

No âmbito civil, é a partir do Código Civil de $1916^{3}$ que ambos os grupos surgem inscritos em lei, já excluídos, porém, da parcela de pessoas consideradas capazes. Mais especificamente, é no Decreto n. 5.484/19284 que se determina que "os índios de qualquer categoria não inteiramente adaptados ficam sob a tutela do Estado, que a exercerá segundo o grau de adaptação de cada um [...]". A condição é reiterada na Lei Federal n. 4.121/19625 , que assim inscreve no então Código Civil: "regime tutelar [...] o qual cessará à medida que se forem adaptando à civilização do País". Os indígenas perduraram nessa condição étnico-constitucional até a promulgação da CF/1988 e do Código Civil atual $(2002)^{6}$, que assume, por fim, que a regulação cabe à legislação especial.

As pessoas com transtornos mentais foram alvo de legislação especial durante o século XX, protagonizada não apenas pela citada lei civil, mas principalmente pelo Decreto n. $24.559 / 1934^{7}$, que, ao dispor "sobre a profilaxia mental, a

\footnotetext{
${ }^{3}$ BRASIL. Lei n. 3.071, de 01 de janeiro de 1916. Código Civil dos Estados Unidos do Brasil. Disponível em: <http://www.planalto.gov.br/ccivil_03/leis/L3071.htm>. Acesso em: 05 set. 2017.

4BRASIL. Decreto n. 5.484, de 27 de junho de 1928. Regula a situação dos índios nascidos no território nacional. Disponível em: <http://www2.camara.leg.br/legin/fed/decret/1920-1929/decreto-5484-27-junho1928-562434-publicacaooriginal-86456-pl.html>. Acesso em: 25 jan. 2018.

${ }^{5}$ BRASIL. Lei n. 4.121, de 27 de agosto de 1962. Dispõe sôbre a situação jurídica da mulher casada. Disponível em: <http://www.planalto.gov.br/CCivil_03/leis/1950-1969/L4121.htm>. Acesso em: 25 jan. 2018.

${ }^{6}$ BRASIL. Lei n. 10.406, de 10 de janeiro de 2002. Institui o Código Civil. Brasília, 2002. Disponível em: <http://www.planalto.gov.br/ccivil_03/leis/2002/L10406.htm>. Acesso em: 05 set. 2017.

${ }^{7}$ BRASIL. Decreto n. 24.559, de 3 de julho de 1934. Dispõe sôbre a profilaxia mental, a assistência e proteção á pessôa e aos bens dos psicopatas, a fiscalização dos serviços psiquiátricos e dá outras providências (sic). Disponivel em: <http://www2.camara.leg.br/legin/fed/decret/1930-1939/decreto-24559-3-julho-1934515889-publicacaooriginal-1-pe.html>. Acesso em: 25 jan. 2018.
} 
assistência e proteção à pessoa e aos bens dos psicopatas", definia que "psicopatas, assim declarados por perícia médica processada em forma regular, são absoluta ou relativamente incapazes de exercer pessoalmente os atos da vida civil". Superada apenas em 2001, sua força normativa serviu a propósitos do importante parque manicomial construído no país ao longo de décadas de institucionalização de centenas de milhares de pessoas ${ }^{8}$. A Lei Federal n. 10.216/20019 (Lei da Reforma Psiquiátrica) anunciou novo tecido normativo, refletor das reformas sanitárias no curso da redemocratização brasileira, e passou a dispor sobre direitos das pessoas com transtornos mentais - e não mais sobre mecanismos de controle dessa população. Cem anos depois da lei civil, entra em vigor a Lei Brasileira de Inclusão das Pessoas com Deficiência ${ }^{10}$, que institui direitos de liberdade dos quais seus titulares foram secularmente alijados, sendo-lhe reconhecida a capacidade civil.

No campo penal, a proximidade é tácita. Suas representações surgem no Código Penal de $1940^{11}$, porém apenas aos loucos era expressamente atribuída a inimputabilidade. Já indígenas seriam alvo de construção interpretativa processual, vingando, desde então, tendência de lhes atribuir ausência total ou parcial de imputabilidade sob justificativa de que, para os interesses penais, eram situados como pessoas com desenvolvimento mental incompleto ou retardo mental ${ }^{12}$. Em referência à citação de Nelson Hungria por Souza Filho, Moreira lembra que, na Exposição de Motivos da propositura do Código Penal, aquele penalista incluiu dentre os "deficientes mentais", o "homo sylvester"13. Esse posicionamento já era também anunciado na crítica de Nina Rodrigues, em 1894, sobre a lei penal anterior, de $1890^{14}$.

Consagra-se, no âmbito penal, o paradigma da integração, em que o acesso a direitos está intimamente relacionado ao grau de adaptação ao padrão cultural hegemônico e resultante da colonização europeia. Em todo caso, evidencia-se a visão estatal de que um "problema de desenvolvimento" residiria no interior de cada

${ }^{8}$ ARBEX, Daniela. Holocausto brasileiro: vida, genocídio e 60 mil mortes no maior hospício do Brasil. 1. ed. São Paulo: Geração Editorial, 2013.

${ }^{9}$ BRASIL. Lei n. 10.216, de 06 de abril de 2001. Dispõe sobre a proteção e os direitos das pessoas portadoras de transtornos mentais e redireciona o modelo assistencial em saúde mental. 2001. Disponível em: <http:// www.planalto.gov.br/ccivil_03/leis/LEIS_2001/L10216.htm>. Acesso em: 25 jan. 2018.

${ }^{10}$ BRASIL. Lei n. 13.146, de 06 de julho de 2015. Dispõe sobre a Lei Brasileira de Inclusão da Pessoa com Deficiência. Disponível em: <http://www.planalto.gov.br/ccivil_03/_ato2015-2018/2015/lei/l13146. htm>. Acesso em: 05 set. 2017.

${ }^{11}$ BRASIL. Decreto-Lei n. 2.848, de 07 de dezembro de 1940. Código Penal. Disponível em: <http://www. planalto.gov.br/ccivil_03/decreto-lei/Del2848compilado.htm>. Acesso em: 05 set. 2017.

${ }^{12}$ SOUZA FILHO, Carlos Frederico Marés de (Coord. Acadêmica). Estatuto dos Povos Indígenas. Brasília-DF: Secretaria de Assuntos Legislativos do Ministério da Justiça, 2009. (Série Pensando o Direito, n. 19/2009). Disponível em: <http://pensando.mj.gov.br/wp-content/uploads/2015/07/19Pensando_Direito3.pdf>.

${ }^{13}$ MOREIRA, Erika Macedo. Onhemoirõ: o Judiciário frente aos direitos indígenas. Tese (Doutorado em Direito) - Programa de Pós-Graduação em Direito, Universidade de Brasília - UnB, 2014. Disponível em: <http:// repositorio.unb.br/bitstream/10482/15760/1/2014_ErikaMacedoMoreira.pdf>.

${ }^{14}$ RODRIGUES, Raymundo Nina. As raças humanas e a responsabilidade penal no Brasil [online]. Rio de Janeiro: Centro Edelstein de Pesquisa Social, 2011. Disponível em: <https://static.scielo.org/scielobooks/ h53wj/pdf/rodrigues-9788579820755.pdf>. 
pessoa louca ou indígena. Em virtude disso, a resposta estatal sempre fora a ação de tentativa de integração, forçada concreta ou simbolicamente, a partir das políticas e instituições especializadas, pois o impasse poderia ser dissolvido, conforme tal compreensão, com a neutralização das singularidades psíquicas, sociais e étnicas atributo dessas pessoas e com sua consequente adesão ao modelo civilizatório.

A breve introdução sobre o paralelismo resultante da condição de subcidadania a que foram, por séculos, submetidos loucos e indígenas será campo de análise sobre avanços e desafios na superação da fase histórica da tutela rumo à fase da garantia de direitos humanos dessas populações, ou mesmo na convivência entre ambos os períodos.

\section{Povos indígenas e tutela}

A história de submissão dos povos autóctones do atual território brasileiro à tutela do Estado nacional deve ser lida no contexto da própria formação da "nação" enquanto tal. Muito embora suas origens remontem aos primórdios da colonização do território brasileiro e ao tipo de relação que historicamente se constituiu entre indígenas e não indígenas (particularmente europeus) ao longo de todo o período colonial, somente com a moderna "nacionalização" dos estados europeus (no caso, Portugal) e, posteriormente, com a independência de suas colônias que a noção de tutela foi propriamente estabelecida como um dispositivo de poder.

Como demonstra Carneiro da Cunha ${ }^{15}$, a compreensão histórica da tutela requer, primeiramente, a distinção entre duas categorias de povos indígenas no período colonial, de acordo com o tipo de relação estabelecido com não indígenas: por um lado, aqueles povos que foram submetidos a um regime de aldeamento, principalmente no contexto das missões de catequização, e que desde muito cedo se viram tutelados por padres e preceptores das companhias religiosas; por outro lado, povos que não se submeteram ao regime de aldeamento das missões, tendo sido chamados de "livres" ou "tribais".

É no contexto da catequização religiosa, portanto, que, de prima, dá-se a relação tutelar entre brancos e indígenas no Brasil, com o consequente estabelecimento de uma relevante divisão entre indígenas tutelados e não tutelados. A tutela, aqui, insere-se no contexto maior da "civilização" de povos indígenas, entendida sobretudo no sentido da conversão cristã e da "domesticação" para o trabalho, objetivos já expostos na carta de Pero Vaz de Caminha - o primeiro registro do encontro entre colonos portugueses e população autóctone do Brasil. Tratava-se, portanto, de um estágio provisório, uma etapa tutelar no processo de incorporação de pessoas provisoriamente incapazes na civilização europeia.

\footnotetext{
${ }^{15}$ CUNHA, M.C. da (Org). História dos Índios no Brasil. São Paulo: FAPESP, Companhia das Letras, SMC, 1992.
} 
As Cartas de Doação e as Cartas Forais eram documentos que poderiam ser denominados de "protoconstitucionais", haja vista sua finalidade de veicular determinações político-administrativas da metrópole para a colônia, sendo os donatários de capitanias hereditárias seus destinatários. Nos documentos do século XVI, já se encontravam ordens de extermínio das aldeias e seus povos, prática que deu significado à primeira etapa da ordem jurídica indigenista ${ }^{16}$.

Ao longo de toda a história brasileira pré-CF/1988, a noção de civilização é indissociável do regime tutelar em todas as suas formas. Essa transitoriedade do "Estado indígena" pré-civilizacional pressupõe uma conflituosa incorporação da população autóctone à sociedade nacional, que até hoje encontra eco em discursos simpáticos à manutenção da tutela como condição jurídica dos povos indígenas no Brasi ${ }^{17}$. Mas ela aponta, sobretudo, para dois objetivos diretamente relacionados com a invenção da nação brasileira: por um lado, o estabelecimento de divisões e diferenciações entre categorias de sujeitos; por outro, a possibilidade de dispor de força de trabalho e riquezas.

Já na metade do século XIX, em querela entre dois autores que mais tarde seriam consagrados como importantes representantes da literatura nacional, o então futuro escritor Manuel Antônio de Almeida apontava com imensa lucidez o significado da proposta de tutela defendida pelo historiador Francisco Adolfo de Varnhagen, que viria a ser reputado como "historiador oficial do Império brasileiro"18. Nos trechos destacados na epígrafe deste texto, Almeida desvela o verdadeiro sentido da proposta de tutela apresentada no manifesto belicista e anti-indígena de Varnhagen: o objetivo era, fundamentalmente, construir argumentação jurídica que justificasse a exploração da mão de obra indígena, sobretudo para viabilizar a subtração das riquezas naturais de suas próprias terras em nome do progresso nacional. A prosperidade desenvolvimentista caminharia junto com o processo civilizatório dos povos indígenas, a despeito de estes constituírem um obstáculo aos interesses nacionais em termos morais ${ }^{19} \mathrm{e}$ econômicos.

Embora, como dito anteriormente, a $\mathrm{CF} / 1988$ reconheça a plena cidadania das populações indígenas do Brasil - o que se reforça com o Decreto n. 5.051/2004²0,

${ }^{16}$ OLIVEIRA, João Pacheco de. Pacificação e tutela militar na gestão de populações e territórios. Mana, Rio de Janeiro, v. 20, n. 1, p. 135-161, abr. 2014. ISSN 0104-9313. Disponível em: <http://www.scielo.br/pdf/ mana/v20n1/a05v20n1.pdf>. http://dx.doi.org/10.1590/S0104-93132014000100005.

${ }^{17}$ LIMA, Antonio Carlos de Souza. O exercício da tutela sobre os povos indígenas: considerações para o entendimento das políticas indigenistas no Brasil contemporâneo. Revista de Antropologia, USP, São Paulo, v. 55, n. 2, 2012. Disponivel em: <http://www.revistas.usp.br/ra/article/view/59301/62337>. https://doi.org/10.11606/2179-0892.ra.2012.59301.

${ }^{18}$ DMITRUK, Hilda B. Repensando os discursos e imagens sobre os indígenas. Cadernos do CEOM, ano 17, $\mathrm{n}$. 18, p. 261-297, ISSN Eletrônico 2175-0173. Arqueologia e populações indígenas. Disponível em: <http:// bell.unochapeco.edu.br/revistas/index.php/rcc/article/download/2225/1307>.

${ }^{19} \mathrm{Cf}$. RODRIGUES, Raymundo Nina. op. cit.

${ }^{20}$ BRASIL. Decreto n. 5.051, de 19 de abril de 2004. Promulga a Convenção n. 169 da Organização Internacional do Trabalho - OIT sobre Povos Indígenas e Tribais. Brasília, 2004. Disponível em: <http:// www.planalto.gov.br/ccivil_03/_ato2004-2006/2004/decreto/d5051.htm>. Acesso em: 05 set. 2017. 
que promulga a Convenção 169 sobre Povos Indígenas e Tribais, da Organização Internacional do Trabalho (OIT) -, é importante recordar que nunca foi oficialmente revogado o Estatuto do Índio, datado de 1973 e nascido no contexto da última ditadura militar. Promulgado pela Lei n. 6.001/1973 ${ }^{21}$, o Estatuto do Índio destaca o "propósito de preservar a sua cultura e integrá-los, progressiva e harmoniosamente, à comunhão nacional" (destaques nossos). Portanto, fica evidente, apesar do avanço constitucional, a manutenção da lógica "assimilacionista" da tutela colonial, baseada em um ideal de civilização dos povos indígenas que significa sua adequação ao sistema produtivo nacional. Contudo, é crescente o entendimento de que a autonomia dos povos indígenas é plena, uma vez que o regime de tutela foi abandonado pela nova ordem constitucional, orientando o poder público ao paradigma da diferença em detrimento do paradigma da incapacidade ${ }^{22}$.

\section{Loucura, institucionalização e tutela}

A história da loucura foi marcada por importante processo de institucionalização, no qual as ciências positivistas tiveram papel fundamental para a invalidação dos sujeitos, bem como para a instauração do paradigma loucura/periculosidade/ invalidação social.

A significação de loucura como doença é algo recente na história ocidental ${ }^{23}$. Desde a Idade Média até a Revolução Francesa e a Revolução Industrial, pessoas loucas faziam parte da vida social das comunidades com aceitação bastante distinta da visão promovida pelo desenvolvimento do pensamento racionalista moderno. Foi no Renascimento que elas começaram a deixar de ser toleradas, passando a ser incluídas nas populações indigentes, delinquentes e demais de comportamentos socialmente indesejados:

Presente na vida quotidiana da Idade Média e familiar a seu horizonte social, o louco, na Renascença, é reconhecido de outro modo; reagrupado, de certa forma, segundo uma nova unidade específica, delimitado por uma prática sem dúvida ambígua que o isola do mundo sem lhe atribuir um estatuto exatamente médico... de certo modo o louco foi absorvido numa massa indiferenciada ${ }^{24}$.

Foucault esclareceu que a institucionalização da loucura e o esforço para sua compreensão deram-se mais como ato jurídico do que como ato da ciência médica/ psiquiátrica. Esta, desde o século XVI, atuou de maneira secundária em relação ao ato jurídico - a ponto de, no século XVIII, toda internação dever ser precedida de interdição civil, pois a loucura passava a ser entendida como incapacitante para a vida civil.

\footnotetext{
${ }^{21}$ BRASIL. Lei n. 6.001, de 19 de dezembro de 1973. Dispõe sobre o Estatuto do Índio. Disponível em: <http://www.planalto.gov.br/ccivil_03/leis/L6001.htm>. Acesso em: 05 set. 2017.

${ }^{22}$ VILLARES, Luiz Fernando. Direito e povos indígenas. 1. ed. Curitiba: Juruá, 2009.

${ }^{23}$ FOUCAULT, Michel. História da loucura na idade clássica. São Paulo: Perspectiva, 2005.

${ }^{24}$ Id. Ibid., p. 121.
} 
É na modernidade que a ciência médica passa a possuir crescente poder hegemônico de definir e estabelecer tudo que diz respeito à doença e às formas de lidar com ela. Com a herança da institucionalização e a partir da noção de que o louco necessariamente é um ser perigoso, a ciência médica passou a construir tratados e definir tratamentos cada vez mais distantes dos sujeitos que vivem a experiência da loucura. Phillipe Pinel possui fundamental importância nesse processo, pois a ele é atribuído o papel de precursor da relação doença-loucura e de inaugurador do hospital psiquiátrico como genuíno local destinado ao tratamento daqueles fenômenos definidos por ele como "desvio das paixões"25. Entretanto, como as "teorias dos primeiros alienistas funcionavam baseadas numa sintomatologia”, foi Bénédict-Augustin Morel (18091873) quem deu início à nova concepção de doença mental - e, logo, de psiquiatria -, inovando com métodos que, para além da classificação dos sintomas, classificavam a etiologia das doenças, com o fim de elaborar um sistema de categorias patológicas ${ }^{26}$.

No processo de urbanização das cidades, o controle da circulação de pessoas, mercadorias e doenças encerra também novo modo de organização social, por meio e em torno da qual se desenvolve a medicina social. A passagem da medicina individual para a medicina urbana (ou medicina social) revela alguns porquês de um tipo determinado de relação entre Estado e populações atualmente ditas em vulnerabilidade - emblema por vezes atribuído aos povos indígenas e, mais notoriamente, aos loucos. Segundo Machado ${ }^{27}$, a medicina é uma área de conhecimento que nem sempre privilegiou a saúde como objeto de estudo, mas sim - e por mais tempo - a doença. Foi o dano orgânico e psíquico que predominou como objeto dessa ciência entre os séculos XVI e XVIII. Antes de serem disparadas as primeiras transformações sociais oriundas da urbanização das principais cidades latino-americanas e europeias, as práticas medicinais dedicavam-se à cura individual. Os estudos epidemiológicos e demográficos ainda não eram desenvolvidos o suficiente para que a área médica passasse a ser primordial para se pensar a política das populações, ao contrário do que ocorreu no início do processo de urbanização das cidades (século XVIII, na Europa, e XIX, no Brasil).

Ademais, no Brasil, ainda que o controle das populações não pautasse as práticas médicas até o século XIX, tais atividades sempre foram controladas pelo Estado, que, também nesse âmbito, já disputava espaço político com os saberes tradicionais de cuidado e cura ${ }^{28}$. Com isso, observa-se a relevância dessa ciência para o Estado português em suas colônias, nas quais não se permitia instalar universidade ou congêneres, o que impediu a proliferação de profissionais e, assim, a promoção

\footnotetext{
${ }^{25}$ MACHADO, Roberto et al. Danação da norma: medicina social e constituição da psiquiatria no Brasil. São Paulo: Graal, 1978.

${ }^{26}$ DONZELOT, Jacques. A polícia das famílias. Rio de Janeiro: Graal, 1980. p. 118.

${ }^{27}$ Id. Ibid.

${ }^{28}$ No início do século XVI, o processo de povoamento das terras brasileiras foi acompanhado da chegada dos primeiros físicos-mores e cirurgiões-mores portugueses, que coordenariam e fiscalizariam trabalhos médicos. Segundo Machado, “a Fisicatura é um tribunal, o Físico-mor, um juiz” (sic). (1978, p. 26).
} 
de autonomia política da colônia. Efeito disso: controle pleno, pelas câmaras municipais, das relações cotidianas entre os poucos médicos autorizados e a população ${ }^{29}$. Foi então que, segundo Caponi, "nas últimas décadas do século XIX e nas primeiras do século XX, começa a se consolidar uma verdadeira biopolítica das populações consideradas de risco (para si e para os outros)" ${ }^{30}$.

O tema das sujeiras nos logradouros públicos despertou a atenção das câmaras municipais para a saúde coletiva. Regiões portuárias foram nomeadas como pauta de urgência para atuação médico-política de controle da circulação de pessoas doentes. Resposta imediata a isso, os lazaretos foram os primeiros galpões de isolamento: passageiros dos navios suspeitos permaneciam em quarentena para não contaminar habitantes da cidade. Verifica-se esse momento como primeiro ilustrador da medicina social no Brasil: práticas de controle das populações frente a vetores contagiosos. Inaugura-se o discurso preventivo do risco. $\mathrm{O}$ hospital psiquiátrico vem a ser o primeiro estabelecimento especializado na defesa da saúde da sociedade. Conforme trata $S z a s z^{31}$ acerca do tratamento psiquiátrico na primeira metade do século XX, “os pacientes psiquiátricos afluentes são geralmente tratados por meio de psicoterapia, enquanto os pacientes pobres são tratados por intervenções físicas”.

Basaglia $^{32}$ alertou que a psiquiatria, por reconhecer a loucura como um fenômeno incompreensível, passou a excluir o louco da possibilidade de convívio social, subjugando-o ao poder médico como única possibilidade de cura. Nesse sentido, a psiquiatria construiu um lugar social de completo apartamento social para a loucura e para o louco. Diagnósticos psiquiátricos adquiriram valor de categoria, etiquetagem, além do qual não existe mais possibilidade de ação ou saída. Loucura passou a significar personificação do perigo na ordem social burguesa, para cujo contingente economicamente emergente, segundo Foucault ${ }^{33}$, mais importante que a exclusão das populações indesejáveis propriamente dita é a produção e o aprimoramento das técnicas que garantem esse fim: mecanismos de exclusão, que, por sua vez, produzem lucros políticos, vantagens decorrentes desse processo de dominação incidente sobre corpos que é efeito do poder circundante. Essas técnicas de "assujeitamento" veiculam discursos que enunciam a invalidação dos indivíduos loucos.

No Brasil, expressões da luta antimanicomial surgem na passagem das décadas de 1970 e 1980, no bojo de iniciativas de reforma sanitária que resultariam

\footnotetext{
${ }^{29} \mathrm{Cf}$. MACHADO, Roberto et al. op. cit.

${ }^{30} \mathrm{CAPONI}$, Sandra. Loucos e degenerados: uma genealogia da psiquiatria ampliada. Rio de Janeiro: Ed. Fiocruz, 2012.

${ }^{31}$ SZASZ, Thomas S. O mito da doença mental: fundamentos de uma teoria da conduta pessoal. São Paulo: Círculo do Livro, 1974. p. 68.

${ }^{32}$ BASAGLIA, Franco. Escritos selecionados em saúde mental e reforma psiquiátrica. Rio de Janeiro: Garamond Universitária, 2005.

${ }^{33}$ FOUCAULT, Michel. Aula de 14 de janeiro de 1976. In: . Em defesa da sociedade: curso no Collège de France (1974-1975). Trad. de. Maria Ermantina Galvão. São Paulo: Martins Fontes, 1999.
} 
na inscrição do Sistema Único de Saúde (SUS) no contexto constitucional ${ }^{34}$. Homonimamente, é a reforma psiquiátrica que questiona, diariamente, o tratamento hegemônico consubstanciado no confinamento em grandes hospitais psiquiátricos, associado ao exercício constante de graves violações de direitos humanos ${ }^{35}$.

Se, conforme Basaglia e Szasz, o hospital psiquiátrico não produz tecnologias de cuidado, são o poder do saber médico e a força física sobre pessoas internadas os principais instrumentos utilizados. Hipermedicalização, contenção física, eletroconvulsoterapia e isolamento são exemplos de técnicas corriqueiramente utilizadas por essas instituições até os tempos atuais, que mais servem para controlar comportamentos tidos como inapropriados do que para produzir cuidado e possibilitar que as pessoas possam aprender a lidar com seu sofrimento. Deixa-se claro que a única possibilidade de existência para sujeitos internados é a total aniquilação da identidade pessoal, a mortificação do $\mathrm{eu}^{36}$.

Ao questionar os fundamentos da ciência psiquiátrica, a reforma psiquiátrica passou a defender a retirada do diagnóstico da centralidade da ação em saúde mental e, dessa maneira, quanto ao sujeito, "recompondo-o, re-contextualizando-o, re-complexificando-o" ${ }^{37}$. Conforme mencionado, a Lei da Reforma Psiquiátrica foi fruto de longa mobilização de diferentes setores da sociedade civil e da saúde pública. Ao redirecionar o modelo assistencial de saúde mental, deslocou o cuidado do modelo cujo centro era o hospital para uma nova direção, visando a serviços em rede com base comunitária. Ao invés do distanciamento e da exclusão pela internação, iniciou uma proposta de cuidado em que a saúde e a reabilitação psicossocial só são possíveis com o reconhecimento da cidadania e do direito de estar e participar do mundo. Abriu-se caminho para a construção de uma política nacional de saúde mental em que saúde e direitos humanos são indissociáveis - porque aquela está contido nestes - e na qual o exercício da cidadania é também condição de saúde, como ampliação da capacidade de contratualidade nas relações sociais ${ }^{38}$.

Contudo, é notória a limitação textual da Lei da Reforma Psiquiátrica, que encerrou apenas direitos de caráter ou em contexto sanitário e cujo conteúdo

\footnotetext{
${ }^{34}$ AMARANTE, Paulo. Loucos pela vida: a trajetória da reforma psiquiátrica no Brasil. Rio de Janeiro: Fiocruz, 2003. ${ }^{35} \mathrm{O}$ contexto histórico manicomial também pode ser visto em $\mathrm{BICHO}$ de sete cabeças. Ficção - 88 minutos - 35mm cor - dolby digital. Direção Laís Bodanzky, Roteiro Luiz Bolognesi. Brasil, 2000. Disponível em: <https://docplayer. com.br/16466347-Bicho-de-sete-cabecas-ficcao-88-minutos-35mm-cor-dolby-digital-direcao-lais-bodanzkyroteiro-luiz-bolognesi-producao-sara-silveira-por.html>; NISE: o coração da loucura. Longa ficção - 108 minutos. Gênero: Drama. Ano de produção: 2015. Direção: Roberto Berliner. Distribuidora: Imagem Filmes, Brasil, 2016.

${ }^{36}$ GOFFMAN, Erving. Manicômios, prisões e conventos. São Paulo: Perspectiva, 2003.

${ }^{37} \mathrm{NICACIO}$, Maria Fernanda de Silvio. Utopia da realidade: contribuições da desinstitucionalização para a invenção de serviços de saúde mental. 2003. (Doutorado em Saúde Coletiva) - Programa de Pós-Graduação da Faculdade de Ciências Médicas, da Universidade Estadual de Campinas, 2003. p. 104. Disponível em: <http://repositorio.unicamp.br/bitstream/REPOSIP/311999/1/Nicacio_MariaFernandadeSilvio_D.pdf>.

${ }^{38}$ SARACENO, Benedetto. A cidadania como forma de tolerância. Revista de Terapia Ocupacional da Universidade de São Paulo, São Paulo, v. 22, n. 2, p. 92-101, maio/ago. 2011. Disponível em: <http://www.revistas.usp.br/ rto/article/view/14126/15944>. https://doi.org/10.11606/issn.2238-6149.v22i2p93-101.
} 
localiza a pessoa não no mundo, mas na relação com o Estado-saúde. Mas, ainda que não tenha avançado sobre direitos de autonomia e participação política, é lei de referência que recebe acolhida e resposta justamente carentes em 2008, quando da assinatura brasileira da Convenção sobre os Direitos da Pessoa com Deficiência $(\mathrm{CDPD})^{39}$, e em 2015, quando da promulgação da Lei Brasileira de Inclusão da Pessoa com Deficiência ${ }^{40}$. Ambos os documentos passam a tratar dos direitos de liberdade e participação política.

A CDPD é o primeiro documento temático a garantir, para além dos sociais, direitos civis e políticos. A alteração do paradigma da incapacidade passa a nomear o Estado como incapaz de atender às singularidades de cada pessoa na diversidade populacional em que se propõe intervir. Com isso, reconhece que, do contrário, o entorno psicossocial e cultural é incapacitante ${ }^{41}$. O paradigma anterior repousava sobre o conceito de discernimento, privilegiando-o como expressão da (in)capacidade, tendo menor importância o meio e o contexto macropolítico em que viviam as pessoas com deficiência.

Trata-se de afastar as barreiras ambientais e atitudinais que, em interação com o impedimento com que convive a pessoa, contribuem para violação dos direitos civis e políticos. E, assim, os direitos deixam de estar condicionados à histórica exigência de "superação da deficiência", dado que "deficiência é uma experiência cultural, e não apenas o resultado de um diagnóstico biomédico de anomalias" ${ }^{42}$.

\section{Da tutela dessas populações}

Tratada como exercício de mediação, a tutela sustenta-se em princípios contraditórios que orientam práticas de repressão e proteção. Segundo Souza Lima ${ }^{43}$, o poder tutelar pode resultar da guerra, do mandato jurídico-político e/ou da visão preconceituosa e discriminatória de um grupo sobre o outro.

Pode-se entender tutela como um elemento fundamentalmente presente nas relações autoritárias - que, muitas vezes, justificam-se a partir da proteção

\footnotetext{
${ }^{39}$ ORGANIZAÇÃO DAS NAÇÕES UNIDAS - ONU. Convenção sobre os Direitos da Pessoa com Deficiência. Disponível em: <http://www.pessoacomdeficiencia.gov.br/app/publicacoes/convencao-sobre-os-direitosdas-pessoas-com-deficiencia>. Acesso em: 05 set. 2017.

${ }^{40}$ ld. Ibid.

${ }^{41}$ OBSERVATORIO DDHH. Derechos Humanos de las Personas con Discapacidad Mental: Diagnóstico de la situación en Chile. Observatório Discapacidad Mental. Disponível em <http://www. observatoriodiscapacidadmental.cl/>. Acesso em: 25 fev. 2018.

${ }^{42}$ DINIZ, Debora; BARBOSA, Lívia and SANTOS, Wederson Rufino dos. Deficiência, direitos humanos e justiça. Sur, Rev. int. direitos human. [online], v. 6, n. 11, p. 69, 2009. ISSN 1806-6445. Disponível em: <http:// www.scielo.br/pdf/sur/v6n11/04.pdf>. http://dx.doi.org/10.1590/S1806-64452009000200004.

${ }^{43}$ LIMA, Antonio Carlos de Souza. Sobre tutela e participação: povos indígenas e formas de governo no Brasil, séculos XX/XXI. Mana, Rio de Janeiro, v. 21, n. 2, ago. 2015. ISSN 0104-9313. Disponível em: <http:// www.scielo.br/pdf/mana/v21n2/0104-9313-mana-21-02-00425.pdf>. http://dx.doi.org/10.1590/0104$93132015 v 21 n 2 p 425$.
} 
ofertada - entre pessoa, grupos ou instituições (tutores) perante mesmos arranjos, porém, mais fracos (tutelados) e, ao mesmo tempo, mediante inevitável (para os tutelados) ou vantajosa (para os tutores) convivência.

Ao emprestar para o período colonial a expressão "pacificação", que atualmente intitula as práticas de dominação e morte de moradores de favelas cariocas por agentes estatais, João Pacheco de Oliveira a reconhece como mecanismo para objetivos similares para os quais concorriam as práticas de "assujeitamento" e morte de indígenas durante os séculos coloniais. Diante disso, o autor afirma que as “pacificações' foram fundamentais para insular os indígenas em pequenas faixas de terras, liberando paralelamente vastos espaços para serem apropriados por interesses privados" 44 .

Adotando esse mesmo raciocínio na análise sobre um terceiro público (os loucos), inclusive com a informada produção de morte em série, pode-se estender a prática de "pacificação" ao modelo de produção e controle hospitalar da loucura, institucionalizado no Brasil desde 1852, com a fundação do Hospital Pedro II, no Rio de Janeiro. A paródia seria acertada: as pacificações (dos loucos nos hospitais) foram fundamentais para insular pessoas com transtornos mentais em pequenas faixas de terra. Ainda, como diz em relação aos indígenas, "é necessário que os tutores imponham aos tutelados uma moralidade (da qual pretensamente estariam desprovidos)" 45 .

Parafraseando Foucault quando abordou o controle das populações a partir da lepra, Lima pode ser citado e, ao mesmo tempo, também parafraseado. Afirma que o "poder tutelar exclui ao criar postos indígenas aos quais os povos autóctones deveriam (re/a)correr e junto aos quais deveriam se segregar" ${ }^{46}$. O mesmo, portanto, vale para as populações loucas.

\section{Autonomia e protagonismo em diferentes expressões}

Nesses diferentes horizontes de mobilização, fortalecidos com a CF/1988, é interessante observar que políticas públicas construídas ao longo dos anos 1990 e da primeira década do século XXI tiveram participação decisiva de movimentos sociais, e nelas habitam duas noções centrais para a articulação de suas práticas e de seus discursos: autonomia e protagonismo. Tanto para os movimentos indígenas e seus parceiros na sociedade civil organizada, como para grupos sociais ligados à luta antimanicomial e à reforma psiquiátrica, a desconstrução da tutela significou a

\footnotetext{
${ }^{44}$ OLIVEIRA, João Pacheco de. Pacificação e tutela militar na gestão de populações e territórios. Mana, Rio de Janeiro, v. 20, n. 1, p. 137, abr. 2014. ISSN 0104-9313. Disponível em: <http://www.scielo.br/pdf/mana/ v20n1/a05v20n1.pdf>. http://dx.doi.org/10.1590/S0104-93132014000100005.

${ }^{45}$ Id. Ibid., p. 138.

${ }^{46}$ LIMA, Antonio Carlos de Souza. Sobre tutela e participação: povos indígenas e formas de governo no Brasil, séculos XX/XXI, cit., p. 801.
} 
afirmação dessas noções, dotadas de sentidos específicos a cada um desses campos de existência e militância política.

No caso dos povos indígenas, noções de autonomia e protagonismo mostraram-se articuladas às particularidades da cidadania indígena, à luta pelo direito dos povos indígenas como sujeitos coletivos, pela autodeterminação e pelo reconhecimento do direito a manterem suas próprias organizações sociais, usos, costumes, tradições, territórios e capacidade postulatória ${ }^{47}$ - luta por, como diz Beltrão e Oliveira, "ser cidadão pleno sem deixar de ser quem são" (destaques dos autores) ${ }^{48}$.

A década de 1970 foi marco nesse processo porque, a partir daí, foram construídas as denominações do movimento indígena no Brasil, cuja organização ganhou escala nacional com a criação da União das Nações Indígenas (UNI) - articulada com outros setores e movimentos em torno do processo de redemocratização e da promulgação da CF/1988. A partir desse momento, obteve-se o reconhecimento legal da organização social indígena e do direito dos índios, suas comunidades e organizações de ingressarem, como partes legítimas, em juízo para a defesa de seus direitos e interesses, nos termos da Carta da República de 1988. Esse processo "provocou mudanças de orientação na atuação política dos indígenas no campo das relações interétnicas", inclusive no pertinente à expectativa e à participação indígenas "sobre o destino da política indigenista oficial":

Uma vez assegurado o direito indígena à terra na Constituição de 1988, abriu-se espaço para outras preocupações emergirem com maior força reivindicativa, como, por exemplo, a proteção dos territórios e a sustentabilidade socioeconômica dos grupos indígenas na sociedade nacional. Um tom mais propositivo foi dado às reivindicações, ao direcionarem as demandas à esfera das políticas públicas, como, por exemplo, as políticas de educação e de saúde diferenciadas para as populações indígenas ${ }^{49}$.

Nas décadas seguintes, testemunhou-se uma maior participação indígena na esfera pública da sociedade e do Estado brasileiros. São exemplos desse processo a própria construção de políticas públicas voltadas à saúde indígena no âmbito do SUS

\footnotetext{
${ }^{47}$ DANTAS, F. A. de C. Os povos indígenas brasileiros e a cidadania ativa. Revista Argumenta, JacarezinhoPR, 5, p. 180-194, fev. 2013. ISSN 2317-3882. Disponível em: <http://seer.uenp.edu.br/index.php/ argumenta/article/view/46/47>. Acesso em: 15 dez. 2015.

${ }^{48}$ BELTRÃO, Jane Felipe; OLIVEIRA, Assis da Costa. Povos indígenas e cidadania: inscrições constitucionais como marcadores sociais da diferença na América Latina. Revista de Antropologia, USP, São Paulo, v. 53, n. 2, p. 715-744, 2010. ISSN 0034-7701, Disponível em: <http://www.revistas.usp.br/ra/article/ view/37388/40421>. https://doi.org/10.11606/2179-0892.ra.2010.37388. p. 715.

${ }^{49}$ MATOS, Maria Helena Ortolan. Rumos do movimento indígena no Brasil contemporâneo: experiências Exemplares no Vale do Javari. Tese (Doutorado em Ciências Sociais). Departamento de Antropologia do Instituto de Filosofia e Ciências Humanas da Universidade Estadual de Campinas, Campinas, 2006. p. 14. Disponível em: <http://repositorio.unicamp.br/jspui/bitstream/REPOSIP/280083/1/Matos_MariaHelenaOrtolan_D. pdf>. Acesso em: 03 out. 2018.
} 
e a realização de conferências nacionais de saúde indígena ${ }^{50}$. No entanto, o cenário político da última década e a intensificação de conflitos interétnicos têm expressado de modo cada vez mais claro que o reconhecimento jurídico não é suficiente para garantir a efetividade dos direitos conquistados, e a lógica tutelar pode se atualizar em novas e diferentes formas. Como lembram Souza Lima e Barroso-Hoffmann, o fim jurídico da tutela da União sobre povos indígenas "não significa o fim de formas de exercício de poder, de moralidade e de interação que se poderia qualificar de tutelares, nem representa novo projeto para o relacionamento entre povos indígenas, poderes públicos e segmentos dominantes da sociedade brasileira" ${ }^{\text {"51 }}$.

A luta por autonomia e protagonismo indígena, também no campo da formulação de políticas públicas de que são destinatários, mantém-se necessária e permanentemente tensionada. O reconhecimento dessas conquistas, ainda que seja relativizado pelas ambiguidades e contradições do papel do Estado no plano das relações interétnicas e pelos diferentes sentidos que a noção de participação possa implicar, não deve, todavia, deixar de ser apontado ${ }^{52}$. Nesse sentido, a promulgação do Decreto n. 7.747/2012 $2^{53}$, e todo o processo que precedeu a formulação da Política Nacional de Gestão Territorial e Ambiental de Terras Indígenas (PNGATI) podem ser vistos como resultado desses esforços, pois, pela primeira vez na construção de uma política de Estado para povos indígenas, partiu-se de um processo de discussão e elaboração reunindo diferentes setores do Estado e representantes dos movimentos indígenas, tendo sido a proposta submetida à consulta dos povos indígenas ${ }^{54}$.

De outro lado, a ampliação do protagonismo das pessoas que sofrem em decorrência de sofrimento psíquico é importante mote de toda ação em saúde mental, tendo em vista que essa é a maior antítese da aniquilação do sujeito e a possibilidade

\footnotetext{
${ }^{50}$ Sobre a criação do Subsistema de Atenção à Saúde Indígena, no âmbito do Ministério da Saúde, e a participação indígena ver Souza Lima (Sobre tutela e participação: povos indígenas e formas de governo no Brasil, séculos XX/XXI, cit., p. 443-444). Sobre as Conferências Nacionais de Saúde Indígena, ver: CONFERÊNCIAS Nacionais de Saúde: contribuições para a construção do SUS. Disponível em: <http:// www.ccs.saude.gov.br/cns/conferencias-indigenas.php>. Acesso em: 03 out. 2018.

${ }^{51}$ LIMA, Antonio Carlos de Souza; BARROSO-HOFFMANN, Maria (Orgs.) Além da tutela: bases para uma nova política indigenista. Rio de Janeiro: Contra Capa Livraria. 2002. p. 17.

${ }^{52}$ SOUZA FILHO, Carlos Frederico Marés de (Coord. Acadêmica). Estatuto dos Povos Indígenas. Brasília-DF: Secretaria de Assuntos Legislativos do Ministério da Justiça, 2009. (Série Pensando o Direito, n. 19/2009). Disponivel em: <http://pensando.mj.gov.br/wp-content/uploads/2015/07/19Pensando_Direito3.pdf>.

${ }^{53}$ BRASIL. Decreto n. 7.747, de 05 de junho de 2012. Institui a Política Nacional de Gestão Territorial e Ambiental de Terras Indígenas - PNGATI, e dá outras providências. Disponível em: <http://www.planalto. gov.br/ccivil_03/_ato2011-2014/2012/decreto/d7747.htm>. Acesso em: 05 set. 2017.

54“O processo de consultas aos povos indígenas para a construção da PNGATI reuniu 1.250 representantes indígenas, pertencentes a 186 povos de todas as regiões do país, que foram mobilizados e indicados pelas organizações indígenas regionais" in BAVARESCO, Andréia; Menezes, Marcela. Entendendo a PNGATI: Política Nacional de Gestão Territorial e Ambiental Indígenas - PNGATI. Decreto n 7.747, de 5 de julho de 2012. Brasília: GIZ; Projeto GATI; Funai, 2014. p. 14. Disponível em: <http://cggamgati.funai.gov.br/files/2414/8839/5161/ Entendendo_a_PNGATI.pdf>. A PNGATI também tem como precedentes experiências de participação indígenas na gestão de projetos governamentais, como no Projeto Demonstrativo dos Povos Indígenas. Ver MANCHINERI, T.; Jacinto, A. B. M. (Org.). Diálogos e saberes: lições, experiências e recomendações dos projetos demonstrativos dos povos indígenas para as políticas públicas. Brasília-DF: MMA; GIZ, 2015.
} 
de superação definitiva da lógica manicomial. Nesse sentido, ações que pudessem ampliar as possibilidades de experiência para usuários do SUS se fortaleceram nos primeiros 15 anos deste século, o que interage com a noção de saúde como capacidade fundamental, que viabiliza o exercício de outras capacidades ${ }^{55}$.

Uma primeira discussão que possui certa tradição no campo da saúde mental brasileira é a questão do trabalho, cujas estratégias de geração de renda e inserção produtiva vinculam-se à dimensão da economia solidária devido à identidade práxica entre esses dois campos. Ainda antes da Lei da Reforma Psiquiátrica, foi promulgada a Lei n. 9.867/199956, que "dispõe sobre a criação e o funcionamento de Cooperativas Sociais, visando à integração social dos cidadãos”. Insere-se, também no cenário normativo da saúde mental, a cooperativa social, que ganha corpo no terreno executivo a partir do Decreto n. 8.163/2013 ${ }^{57}$, ao criar o Programa Nacional de Apoio ao Associativismo e Cooperativismo Social (Pronacoop Social).

A política habitacional mostrou-se como outra importante questão, tendo em vista que, em face dos eventuais rompimentos de laços sociais e familiares, a moradia também costuma ser precarizada, acentuando-se a experiência do sofrimento.

Se o paradigma da tutela possibilita observar paralelos entre os campos da saúde mental e das questões indígenas, é também possível encontrar comunicações assecuratórias em práticas que se contrapõem à tutela, seja na defesa dos direitos indígenas, seja em relação aos direitos das pessoas com transtornos mentais. Nas situações citadas acima, a luta pela autonomia reúne esses distintos campos e sujeitos sociais em reivindicações de reconhecimento de seus modos de viver, do direito de produzir e cuidar com autonomia de seus territórios de vida - seja em uma terra indígena, seja na cidade -, de suas relações sociais e dos frutos do trabalho.

\section{Caminhos de bem viver: encontros possíveis entre saúde mental e direitos indígenas}

Tendo estabelecido o paralelo entre esses dois campos de mobilização social e informado a repercussão de seus esforços políticos na construção de políticas públicas no Brasil, vislumbram-se novas possibilidades de articulação entre os campos, oferecidas pela noção de "bem viver".

\footnotetext{
${ }^{55}$ NOGUEIRA, Roberto Passos. Perspectivas críticas acerca da relação entre saúde e desenvolvimento com foco nos Países BRIC. Análise Econômica, Porto Alegre, ano 30, n. especial, p. 75-95, set. 2012. Disponível em: <http://seer.ufrgs.br/AnaliseEconomica/article/view/26226/21541>. https://doi. org/10.22456/2176-5456.26226.

${ }^{56}$ BRASIL. Lei n. 9.867, de 10 de novembro de 1999. Dispõe sobre a criação e o funcionamento de Cooperativas Sociais, visando à integração social dos cidadãos, conforme especifica. Disponível em: <http://www.planalto.gov.br/ccivil_03/Leis/L9867.htm>. Acesso em: 25 fev. 2018.

${ }^{57}$ BRASIL. Decreto n. 8.163, de 20 de dezembro de 2013. Institui o Programa Nacional de Apoio ao Associativismo e Cooperativismo Social - Pronacoop Social, e dá outras providências. Disponível em: <http://www.planalto. gov.br/ccivil_03/_ato2011-2014/2013/decreto/d8163.htm>. Acesso em: 25 fev. 2018.
} 
Trata-se de conceito originário de povos andinos, elaborado politicamente por movimentos indígenas da América Latina, vinculado à discussão sobre plurinacionalidade e reconhecido nas constituições da Bolívia e do Equador ${ }^{58}$. Como destaca Schavetzon, há várias traduções possíveis do conceito aimará de Vivir Bien e do conceito quechua de Buen Vivir, devendo-se observar sua polissemia como categoria de pensamento, bem como a diversidade de usos e aplicações possíveis ${ }^{59}$.

No entanto, ainda que o Vivir Bien/Buen Vivir seja visto como conceito que superou fronteiras etimológicas originais ao ser traduzido para a linguagem das organizações políticas, Schavetzon destaca sentidos que têm mantido sua força semântica, ressaltando "el puente que llega al Estado desde la comunidade y el pensamento indígena"- a ponte que chega ao Estado a partir da comunidade e do pensamento indígena. Para a conclusão deste trabalho e dos paralelos que ele procura construir, na polissemia da categoria importa guardar sentidos que apontem para conexões entre "saber vivir" no cotidiano, "saber morir" e desejos de vida plena, de relação com a "Madre Tierra y la comunidad" - imagens que permitiram articulação de discursos de descolonização, de crítica ao modelo econômico dominante e à noção estreita de desenvolvimento, de discussão sobre uma filosofia e forma de vida sustentadas nas comunidades, em autonomia e autodeterminação. Viver, morar, trabalhar, participar: instâncias relacionadas e interdependentes que aproximam indivíduos, comunidades, ambientes, territórios e povos.

A noção de "bem viver" também tem sido referência, em diversos contextos indígenas na América Latina, para a construção de relações com políticas públicas e a afirmação de direitos, havendo aproximações possíveis aos princípios da reforma psiquiátrica. O campo da saúde mental pressupõe, em contextos mais convencionalmente ligados às reformas psiquiátrica e sanitária, que as ações tenham como norte interesses, desejos e necessidades próprios de cada sujeito ou coletivo com que se trabalha ${ }^{60}$, considerando suas referências de bem-estar, e nesse sentido, de bem viver. Particularmente em função de demandas graves relacionadas a altas taxas de suicídios em alguns povos indígenas no Brasil, e também em função de necessidades decorrentes do uso de álcool ${ }^{61}$, o modelo de atenção

\footnotetext{
${ }^{58}$ MANAMI, Fernando Huanacuni. Vivir Bien/Buen Vivir: filosofia, políticas, estratégias, experiências regionales. III CAB, Bolivia, 2010. Coodinadora Andina de Organizaciones Indígnas - CAOI. Disponível em: <https://www.escrnet.org/sites/default/files/Libro\%20Buen\%20Vivir\%20y\%20Vivir\%20Bien_0.pdf>. Acesso em: 03 out. 2018.

${ }^{59}$ SCHAVETZON, S. Plurinacionalidad y Vivir Bien/Buen Vivir: dos conceptos leídos desde Bolivia e Ecuador post-constituyentes. Ediciones Abya-Yala, CLACSO, Quito-Ecuador, 2015. p. 181. Disponível em: <http:// biblioteca.clacso.edu.ar/clacso/se/20160202103454/Plurinacionalidad.pdf>. Acesso em: 03 out. 2018.

${ }^{60}$ MOTA, Taia Duarte. As necessidades de saúde da perspectiva dos usuários de um serviço comunitário de saúde mental. Dissertação (Mestrado em Enfermagem Psiquiátrica) - Programa de Pós-Graduação em Enfermagem da Escola de Enfermagem da Universidade de São Paulo, 2007. Disponível em: <http://www. teses.usp.br/teses/disponiveis/7/7134/tde-20042007-101132/pt-br.php>.

${ }^{61}$ LANGDON, E. J. 0 que beber, como beber e quando beber: o contexto sociocultural no alcoolismo entre as populações indígenas. In: SEMINÁRIO SOBRE ALCOOLISMO E VULNERABILIDADE ÀS DST/AIDS ENTRE OS POVOS INDÍGENAS DA MACRORREGIÃO SUL, SUDESTE E MATO GROSSO DO SUL. Anais... Brasilia, DF: 2001. p. 83-97.
} 
psicossocial afirmado pelo SUS e pelo Subsistema de Saúde Indígena vem sendo desafiado profundamente a se reinventar para oferecer um cuidado efetivo e que respeite os direitos e as culturas indígenas ${ }^{62,63}$.

Os processos de mudança de orientação política ocorridos no Equador e na Bolívia e a nova constitucionalização que os reconheceu como Estados plurinacionais associaram-se também à eleição de governos mais próximos a movimentos indígenas e ao fortalecimento dos movimentos sociais. Em decorrência, como mencionado, a noção de bem viver ganhou status de princípio constitucional. No caso brasileiro, embora haja iniciativas baseadas na noção de "bem viver" em ações e debates referentes a direitos indígenas - inclusive, em situações relacionadas à saúde mental -, é incipiente a discussão mais ampla e aprofundada a esse respeito. Nesse sentido, observa-se que um aprofundamento sobre a noção de "bem viver" associa-se à perspectiva do processo emancipatório dos povos, dado que se trata de uma categoria que tem pleno sentido político somente em virtude do protagonismo dos próprios interessados ${ }^{64}$.

A percepção de que, mesmo no âmbito dos Estados nacionais, seja possível considerar perspectivas mais plurais e diversas na formulação e realização de políticas públicas aponta para um caminho importante na superação efetiva da história de relações tutelares às quais povos indígenas e pessoas com transtornos mentais foram submetidas no Brasil. Para além da mera inclusão em determinada ordem estabelecida, a cidadania efetiva pressupõe direito à participação nas decisões políticas, inclusive na construção dos projetos coletivos, com autonomia e protagonismo.

\section{Referências}

AMARANTE, Paulo. Loucos pela vida: a trajetória da reforma psiquiátrica no Brasil. Rio de Janeiro: Fiocruz, 2003.

ARBEX, Daniela. Holocausto brasileiro: vida, genocídio e 60 mil mortes no maior hospício do Brasil. 1. ed. São Paulo: Geração Editorial, 2013.

ASSIS, Jaqueline Tavares de et al. Política de saúde mental no novo contexto do Sistema Único de Saúde: regiões e redes Revista Divulgação em Saúde para Debate. Rio de Janeiro, p. 88-113, out. 2014. Disponível em: <http://cebes.org.br/site/wp-content/uploads/2014/12/ Divulgacao-52.pdf $>$.

\footnotetext{
${ }^{62}$ BRASIL. Ministério da Saúde. Portaria n. 2.759, de 25 de outubro de 2007. Diretrizes gerais para a Política de Atenção Integral à Saúde Mental das Populações Indígenas. Disponível em: <http://bvsms.saude.gov. br/bvs/saudelegis/gm/2007/prt2759_25_10_2007.html>. Acesso em: 02 mar. 2018.

${ }^{63}$ ASSIS, Jaqueline Tavares de et al. Política de saúde mental no novo contexto do Sistema Único de Saúde: regiões e redes Revista Divulgação em Saúde para Debate. Rio de Janeiro, p. 88-113, out. 2014. Disponível em: <http://cebes.org.br/site/wp-content/uploads/2014/12/Divulgacao-52.pdf>.

${ }^{64}$ MACDOWELL, Pedro de Lemos. Sujeito e subjetivação no pensamento ameríndio, ou por um diálogo entre a etnologia e a saúde mental. 2015. 63 f. Monografia (Especialização em Saúde Mental, Álcool e Outras Drogas) - Departamento de Psicologia. Universidade de Brasília, Brasília, 2015. Disponível em: <http:// bdm.unb.br/bitstream/10483/11303/1/2015_PedrodeLemosMacdowell.pdf>.
} 
BASAGLIA, Franco. Escritos selecionados em saúde mental e reforma psiquiátrica. Rio de Janeiro: Garamond Universitária, 2005.

BAVARESCO, Andréia; Menezes, Marcela. Entendendo a PNGATI: Política Nacional de Gestão Territorial e Ambiental Indígenas - PNGATI. Decreto $\mathrm{n}^{\circ}$ 7.747, de 5 de julho de 2012. Brasília: GIZ; Projeto GATI; Funai, 2014. Disponível em: <http://cggamgati.funai.gov. br/files/2414/8839/5161/Entendendo_a_PNGATI.pdf>.

BELTRÃO, Jane Felipe; OLIVEIRA, Assis da Costa. Povos indígenas e cidadania: inscrições constitucionais como marcadores sociais da diferença na América Latina. Revista de Antropologia, USP, São Paulo, v. 53, n. 2, p. 715-744, 2010. ISSN 0034-7701, Disponível em: <http://www.revistas.usp.br/ra/article/view/37388/40421>. https://doi.org/10.11606/21790892.ra.2010.37388.

BICHO de sete cabeças. Ficção - 88 minutos - 35mm - cor - dolby digital. Direção Laís Bodanzky, Roteiro Luiz Bolognesi. Brasil, 2000. Disponível em: <https://docplayer.com. br/16466347-Bicho-de-sete-cabecas-ficcao-88-minutos-35mm-cor-dolby-digital-direcaolais-bodanzky-roteiro-luiz-bolognesi-producao-sara-silveira-por.html>.

CAPONI, Sandra. Loucos e degenerados: uma genealogia da psiquiatria ampliada. Rio de Janeiro: Ed. Fiocruz, 2012.

CONFERÊNCIAS Nacionais de Saúde: contribuições para a construção do SUS. Conferências Indígenas. Disponível em: <http://www.ccs.saude.gov.br/cns/conferencias-indigenas.php $>$. Acesso em: 03 out. 2018.

CUNHA, Cilaine Alves. Apresentação de "Civilização dos indígenas. Duas palavras do autor do Memorial Orgânico", de Manuel Antônio de Almeida. Teresa revista de Literatura Brasileira, São Paulo, v. 17, p. 191-199, 2016. ISSN Eletrônico: 2447-8997. Disponível em: <https://www.revistas.usp.br/teresa/article/view/127373/124575>. https://doi.org/10.11606/ issn.2447-8997.teresa.2016.127373.

CUNHA, M.C. da (Org). História dos Índios no Brasil. São Paulo: FAPESP, Companhia das Letras, SMC, 1992.

DANTAS, F. A. de C. Os povos indígenas brasileiros e a cidadania ativa. Revista Argumenta, Jacarezinho-PR, 5, p. 180-194, fev. 2013. ISSN 2317-3882. Disponível em: <http://seer.uenp. edu.br/index.php/argumenta/article/view/46/47>. Acesso em: 15 dez. 2015.

DINIZ, Debora; BARBOSA, Lívia and SANTOS, Wederson Rufino dos. Deficiência, direitos humanos e justiça. Sur, Rev. int. direitos human. [online], v. 6, n. 11, p. 64-77, 2009. ISSN 1806-6445. Disponível em: <http://www.scielo.br/pdf/sur/v6n11/04.pdf>. http://dx.doi. org/10.1590/S1806-64452009000200004.

DMITRUK, Hilda B. Repensando os discursos e imagens sobre os indígenas. Cadernos do CEOM, ano 17, n. 18, p. 261-297, ISSN Eletrônico 2175-0173. Arqueologia e populações indígenas. Disponível em: <http://bell.unochapeco.edu.br/revistas/index.php/rcc/article/ download/2225/1307>. 
Índios e loucos: sobre tutela e cidadania no campo da saúde mental

DONZELOT, Jacques. A polícia das famílias. Rio de Janeiro: Graal, 1980.

FOUCAULT, Michel. Aula de 14 de janeiro de 1976. In: Em defesa da sociedade: curso no Collège de France (1974-1975). Trad. de. Maria Ermantina Galvão. São Paulo: Martins Fontes, 1999.

. História da loucura na idade clássica. São Paulo: Perspectiva, 2005.

GOFFMAN, Erving. Manicômios, prisões e conventos. São Paulo: Perspectiva, 2003.

LANGDON, E. J. O que beber, como beber e quando beber: o contexto sociocultural no alcoolismo entre as populações indígenas. In: SEMINÁRIO SOBRE ALCOOLISMO E VULNERABILIDADE ÀS DST/AIDS ENTRE OS POVOS INDÍGENAS DA MACRORREGIÃO SUL, SUDESTE E MATO GROSSO DO SUL. Anais... Brasília, DF: 2001. p. 83-97.

LIMA, Antonio Carlos de Souza. O exercício da tutela sobre os povos indígenas: considerações para o entendimento das políticas indigenistas no Brasil contemporâneo. Revista de Antropologia, USP, São Paulo, v. 55, n. 2, 2012. Disponível em: <http://www. revistas.usp.br/ra/article/view/59301/62337>. https://doi.org/10.11606/2179-0892. ra.2012.59301.

. Sobre tutela e participação: povos indígenas e formas de governo no Brasil, séculos XX/XXI. Mana, Rio de Janeiro, v. 21, n. 2, p. 425-457, ago. 2015. ISSN 0104-9313. Disponível em: <http://www.scielo.br/pdf/mana/v21n2/0104-9313-mana-21-02-00425.pdf>. http:// dx.doi.org/10.1590/0104-93132015v21n2p425.

LIMA, Antonio Carlos de Souza; BARROSO-HOFFMANN, Maria (Orgs.) Além da tutela: bases para uma nova política indigenista. Rio de Janeiro: Contra Capa Livraria. 2002.

MACDOWELL, Pedro de Lemos. Sujeito e subjetivação no pensamento ameríndio, ou por um diálogo entre a etnologia e a saúde mental. 2015. 63 f. Monografia (Especialização em Saúde Mental, Álcool e Outras Drogas) - Departamento de Psicologia. Universidade de Brasília, Brasília, 2015. Disponível em: <http://bdm.unb.br/bitstream/10483/11303/1/2015_ PedrodeLemosMacdowell.pdf $>$.

MACHADO, Roberto et al. Danação da norma: medicina social e constituição da psiquiatria no Brasil. São Paulo: Graal, 1978.

MANAMI, Fernando Huanacuni. Vivir Bien/Buen Vivir: filosofia, políticas, estratégias, experiências regionales. III CAB, Bolivia, 2010. Coodinadora Andina de Organizaciones Indígnas - CAOI. Disponível em: <https://www.escr-net.org/sites/default/files/Libro\%20 Buen\%20Vivir\%20y\%20Vivir\%20Bien_0.pdf >.

MANCHINERI, T.; Jacinto, A. B. M. (Org.). Diálogos e saberes: lições, experiências e recomendações dos projetos demonstrativos dos povos indígenas para as políticas públicas. Brasília-DF: MMA; GIZ, 2015. 
MATOS, Maria Helena Ortolan. Rumos do movimento indígena no Brasil contemporâneo: experiências Exemplares no Vale do Javari. Tese (Doutorado em Ciências Sociais). Departamento de Antropologia do Instituto de Filosofia e Ciências Humanas da Universidade Estadual de Campinas, Campinas, 2006. Disponível em: $<$ http://repositorio.unicamp.br/jspui/ bitstream/REPOSIP/280083/1/Matos_MariaHelenaOrtolan_D.pdf>.

MOREIRA, Erika Macedo. Onhemoirõ: o Judiciário frente aos direitos indígenas. Tese (Doutorado em Direito) - Programa de Pós-Graduação em Direito, Universidade de Brasília - UnB, 2014. Disponível em: <http://repositorio.unb.br/bitstream/10482/15760/1/2014_ ErikaMacedoMoreira.pdf $>$.

MOTA, Taia Duarte. As necessidades de saúde da perspectiva dos usuários de um serviço comunitário de saúde mental. Dissertação (Mestrado em Enfermagem Psiquiátrica) Programa de Pós-Graduação em Enfermagem da Escola de Enfermagem da Universidade de São Paulo, 2007. Disponível em: <http://www.teses.usp.br/teses/disponiveis/7/7134/ tde-20042007-101132/pt-br.php>.

NICACIO, Maria Fernanda de Silvio. Utopia da realidade: contribuições da desinstitucionalização para a invenção de serviços de saúde mental. 2003. (Doutorado em Saúde Coletiva) - Programa de Pós-Graduação da Faculdade de Ciências Médicas, da Universidade Estadual de Campinas, 2003. Disponível em: <http://repositorio.unicamp.br/ bitstream/REPOSIP/311999/1/Nicacio_MariaFernandadeSilvio_D.pdf $>$.

NISE: o coração da loucura. Longa ficção - 108 minutos. Gênero: Drama. Ano de produção: 2015. Direção: Roberto Berliner. Distribuidora: Imagem Filmes, Brasil, 2016.

NOGUEIRA, Roberto Passos. Perspectivas críticas acerca da relação entre saúde e desenvolvimento com foco nos Países BRIC. Análise Econômica, Porto Alegre, ano 30, n. especial, p. 75-95, set. 2012. Disponível em: <http://seer.ufrgs.br/AnaliseEconomica/article/ view/26226/21541>. https://doi.org/10.22456/2176-5456.26226.

OBSERVATORIO DDHH. Derechos Humanos de las Personas con Discapacidad Mental: Diagnóstico de la situación en Chile. Observatório Discapacidad Mental. Disponível em <http://www.observatoriodiscapacidadmental.cl/>. Acesso em: 25 fev. 2018.

OLIVEIRA, João Pacheco de. Pacificação e tutela militar na gestão de populações e territórios. Mana, Rio de Janeiro, v. 20, n. 1, p. 135-161, abr. 2014. ISSN 01049313. Disponível em: <http://www.scielo.br/pdf/mana/v20n1/a05v20n1.pdf>. http://dx.doi.org/10.1590/S0104-93132014000100005.

ORGANIZAÇÃO DAS NAÇÕES UNIDAS - ONU. Convenção sobre os Direitos da Pessoa com Deficiência. Disponível em: <http://www.pessoacomdeficiencia.gov.br/app/publicacoes/ convencao-sobre-os-direitos-das-pessoas-com-deficiencia>. Acesso em: 05 set. 2017.

RODRIGUES, Raymundo Nina. As raças humanas e a responsabilidade penal no Brasil [online]. Rio de Janeiro: Centro Edelstein de Pesquisa Social, 2011. Disponível em: <https:// static.scielo.org/scielobooks/h53wj/pdf/rodrigues-9788579820755.pdf>. 
Índios e loucos: sobre tutela e cidadania no campo da saúde mental

SARACENO, Benedetto. A cidadania como forma de tolerância. Revista de Terapia Ocupacional da Universidade de São Paulo, São Paulo, v. 22, n. 2, p. 92-101, maio/ago. 2011. Disponível em: <http://www.revistas.usp.br/rto/article/view/14126/15944>. https://doi. org/10.11606/issn.2238-6149.v22i2p93-101.

SCHAVETZON, S. Plurinacionalidad y Vivir Bien/Buen Vivir: dos conceptos leídos desde Bolivia e Ecuador post-constituyentes. Ediciones Abya-Yala, CLACSO, Quito-Ecuador, 2015. Disponível em: <http://biblioteca.clacso.edu.ar/clacso/se/20160202103454/Plurinacionalidad.pdf >.

SOUZA FILHO, Carlos Frederico Marés de (Coord. Acadêmica). Estatuto dos Povos Indígenas. Brasília-DF: Secretaria de Assuntos Legislativos do Ministério da Justiça, 2009. (Série Pensando o Direito, n. 19/2009). Disponível em: <http://pensando.mj.gov.br/wp-content/ uploads/2015/07/19Pensando_Direito3.pdf >.

SZASZ, Thomas S. O mito da doença mental: fundamentos de uma teoria da conduta pessoal. São Paulo: Círculo do Livro, 1974.

VILLARES, Luiz Fernando. Direito e povos indígenas. 1. ed. Curitiba: Juruá, 2009.

Andréa Borghi Moreira Jacinto - Doutora em Antropologia pela Universidade de Brasília; mestre em Antropologia Social pela Universidade Estadual de Campinas; graduada em Ciências Sociais pela Universidade Estadual de Campinas. Analista Técnica de Políticas Sociais na Coordenação Geral de Saúde Mental, Álcool e outras Drogas do Ministério da Saúde. Brasília/DF, Brasil. E-mail: borghi1@yahoo.com.br

Adolpho Daltin Assis - Mestrando no Programa de Pós-Graduação em Direitos Humanos da Universidade Federal da Paraíba; mestre profissional no tema Adolescente em Conflito com a Lei pela Universidade Bandeirantes/Anhanguera; especialista em Gestão de Redes de Atenção à Saúde pela Fundação Oswaldo Cruz/Ministério da Saúde; graduado em Direito pela Pontifícia Universidade Católica de São Paulo. Analista Técnico de Políticas Sociais no Distrito Sanitário Especial Indígena Potiguara, Secretaria Especial de Saúde Indígena do Ministério da Saúde. João Pessoa/PB, Brasil.E-mail: danieladolpho@gmail.com

Pedro de Lemos MacDowell - Mestre em Antropologia Social pela Universidade de Brasília (UNB); especialista em Saúde Mental, Álcool e outras Drogas pela UNB; graduado em Ciências Sociais pela UNB. Analista Técnico de Políticas Sociais no Distrito Sanitário Especial Indígena Guamá-Tocantins, Secretaria Especial de Saúde Indígena do Ministério da Saúde. Belém/PA, Brasil.E-mail: pedro.macdowell@gmail.com

Taia Duarte Mota - Mestre em Enfermagem pela Universidade de São Paulo (USP); graduada em Enfermagem pela USP. Analista Técnica de Políticas Sociais na Coordenação Geral de Saúde Mental, Álcool e outras Drogas do Ministério da Saúde. Brasília/DF, Brasil. E-mail: taiaduarte80@gmail.com 